IOS Press

\title{
Editorial
}

\section{Innovative Medicines development in Europe}

Scientific progress provides new opportunities to respond to still present unmet medical needs. In particular, the emerging innovative approaches for the development of medicinal products offer the promise of novel and more efficacious therapeutic treatments for those neglected pathologies, such as genetic diseases, rare disorders and, as a consequence, disorders affecting the paediatric population.

In the recent years, the differences in the regulatory environment present in each Member State, with the consequent pharmaceutical market fragmentation, have halted the development of innovative strategies for drug development. This is of particular relevance in the area of genetic engineering and cellular biology, which are expected to allow the development of new therapeutic approaches also for "niche" pathologies, to date still untreated, which so far have been considered by the pharmaceutical enterprises a too risky target in order to ensure sufficient investment return. However, the pharmaceutical setting is slowly changing and we are now assisting at a growing interest, particularly by SMEs and biotechnology companies, towards the opportunities in terms of market access offered by pathologies affecting small populations.

Nevertheless, over the past years scientific and technological advances in the treatment of diseases have dramatically outpaced these changes in the financial and social structure of healthcare delivery and innovation. This disparity has stimulated intensive, important and interesting debate between medical professionals, industry and government regulators. Indeed, the assessment of drug innovation is a burning issue because it involves so many different perspectives, mainly those of patients, decision- and policy-makers, regulatory authorities and pharmaceutical companies. Moreover, the innovative value of a new medicine is usually an intrinsic property of the compound, but it also depends on the specific context in which the medicine is introduced and the availability of other medicines for treating the same clinical condition.

The emerging debate revolves around each individual's right to new forms of healthcare, which new medicines, technologies and tests should become available to all citizens and how could these national decisions fit into and affect a global pattern of healthcare delivery. The current answers have so far mystified innovators and consumers as to the value of those technologies and the wisdom of investing on healthcare technologies in general. Indeed, at present societal expectations about drug safety and efficacy are rising while productivity in the pharmaceutical industry is falling.

With the aim to contain this trend, several initiatives have been introduced in Europe and US with the intent of modernizing drug development by incorporating 
into the process recent scientific advances, such as genomics and advanced imaging technologies, and contemplating provisions to promote public-private partnerships and consortia to accomplish the needed research.

The European Medicines Agency (EMA), in order to maintain and stimulate the growing research activity in the area of technical development and scientific innovation, is determined to provide a new regulatory context aimed at satisfying the expectations of the operators in the area, ensuring an harmonised market access and a new legislation which can guarantee the most stringent criteria of quality and safety for human health protection.

Selective incentives provided by the European regulations drive the research towards fields with most therapeutic needs and towards rare and neglected diseases which, without bright social policies, would remain at the border of the process and devoid of the advantages coming from technological improvements. If the incidence of the disease is no longer the criteria to drive research strategies, therapies can become personalised thanks to the growing knowledge in the field of genetic, molecular chemistry and biochemistry. Relevant examples of the European initiatives are concentrated in the three following instruments:

1. The European Regulation on "Advanced Therapies"- encopassing gene therapy, somatic cell therapy and tissue engineered products

2. The European Regulation on 'Orphan Medicinals products, the first Regulation providing incentives to stimulate research in uncovered fields

3. The Paediatric Regulation, aimed at closing the gap in paediatric research and drug development.

From all of these, valuable contribution is expected.

José Luis Valverde and Adriana Ceci

Co-editors

\section{References}

[1] http://www.ema.europa.eu/pdfs/human/cpwp/41086906enfin.pdf.

[2] http://ec.europa.eu/enterprise/pharmaceuticals/eudralex/vol-1/reg 2000 847/reg 2000842 en.pdf.

[3] http://ec.europa.eu/enterprise/pharmaceuticals/eudralex/vol-1/reg 2000 141/reg 2000141 en.pdf.

[4] http://ec.europa.eu/enterprise/pharmaceuticals/eudralex/vol1/reg_2006_1901/reg_2006_1901_en.pdf.

[5] http://ec.europa.eu/enterprise/pharmaceuticals/eudralex/vol1/reg_2006_1902/reg_2006_1902_en.pdf. 